\title{
(2) OPEN ACCESS \\ Hemidiaphragmatic paralysis related to extravasation of parenteral solution in very low birthweight neonates
}

\author{
Hai-Bo Huang, ${ }^{1}$ Qian-Shen Zhang, ${ }^{1}$ David G Tingay, ${ }^{2,3}$ Po-Yin Cheung ${ }^{4}$
}

\begin{abstract}
${ }^{1} \mathrm{NICU}$, University of Hong KongShenzhen Hospital, Shenzhen, Guangdong, China

${ }^{2}$ Neonatology, Royal Children's Hospital, Parkville, Victoria, Australia

${ }^{3}$ Neonatal Research, Murdoch Childrens Research Institute, Parkville, Victoria, Australia ${ }^{4}$ Neonatal Inetnsive Care, University of Alberta, Edmonton, Alberta, Canada
\end{abstract}

Correspondence to Professor Po-Yin Cheung; poyin@ualberta.ca

Accepted 15 April 2021

Check for updates

(c) BMJ Publishing Group Limited 2021. Re-use permitted under CC BY-NC. No commercial re-use. See rights and permissions. Published by BMJ.

To cite: Huang $\mathrm{H}-\mathrm{B}$,

Zhang Q-S, Tingay DG,

et al. BMJ Case Rep

2021:14:e242390.

doi:10.1136/bcr-2021

242390

\section{SUMMARY}

Central venous catheter (CVC) placement is common in the care of very low birthweight (VLBW) preterm neonates. Although it is generally considered to be safe, CVC placement is associated with complications, including extravasation that may lead to significant morbidity and mortality. We report the clinical course of an extremely preterm neonate born at 27 weeks gestation, and another 5 VLBW preterm neonates reported in the literature with hemidiaphragmatic paralysis related to extravasation of parenteral solution from CVC placement. In VLBW preterm neonates, spontaneous recovery of diaphragmatic paralysis related to extravasation of parenteral solution is possible.

\section{BACKGROUND}

Phrenic nerve injury during central venous catheter (CVC) insertion can rarely be responsible for hemidiaphragmatic paralysis in critically ill neonates. Direct nerve injury during the insertion of CVC through the subclavian vein, ${ }^{1}$ thoracic surgery, traumatic delivery (brachial plexus injury) ${ }^{2}$ have been reported as the causes of hemidiaphragmatic paralysis. There are a few case reports on the extravasation of parenteral solution from CVC. ${ }^{3-6}$ We reported the clinical course and management of hemidiaphragmatic paralysis following the extravasation of parenteral fluid in a very low birthweight (VLBW) neonate at extremely preterm gestation in our centre. We also discussed the different clinical presentations and management of hemidiaphragmatic paralysis in this population.

\section{CASE PRESENTATION}

A preterm female (birth weight $800 \mathrm{~g}$ ) was born at 27 weeks gestation to a 29 -year-old primid gravida mother. Ultrasound scans during the pregnancy were normal. The pregnancy was complicated by chronic hypertension and gestational diabetes mellitus. Two weeks prior to delivery, the mother had cholecystitis that was treated with a 5-day course of antibiotics and had a full course antenatal steroids prophylaxis and magnesium sulfate infusion. There was no premature rupture of membrane nor intra partum complication. The neonate was born by spontaneous, uneventful vaginal delivery after delayed cord clamping for 60s with Apgar scores of 8,9 and 9 at 1 st, 5 th and 10 th minutes of life, respectively. The neonate had mild respiratory distress syndrome requiring biphasic continuous positive airway pressure support with $21 \%$ oxygen.
At 7 hours after birth, a peripherally inserted central catheter (PICC, 1.9Fr single lumen, Hao Lang Science and Technology, Foshan, China) was inserted through the right basilic vein after failed placement of umbilical venous catheter. The catheter tip was placed at the proximal end of right subclavian vein (figure 1A). At 20 hours of life, she was intubated and ventilated for progressive respiratory distress, porcine surfactant $(120 \mathrm{mg} / \mathrm{kg})$ was given. At 30 hours after birth, there was oedema of the right neck and shoulder noted, and chest X-ray confirmed right pleural effusion (figure 1B).

\section{INVESTIGATIONS}

Pleural paracentesis was performed for diagnostic and therapeutic purposes. Approximately $50 \mathrm{~mL}$ of milky fluid chemically identical to parenteral nutrition solution was aspirated using a $16 \mathrm{G}$ thoracentesis catheter (\#20173660234, Foshan Special Medical, Foshan, China). Two days after the needle aspiration of pleural effusion, chest X-ray showed elevated right hemidiaphragm (figure 1C). After an unsuccessful extubation on D11, right hemidiaphragmatic paralysis was confirmed by diaphragmatic ultrasound on D13 (video 1). During the hospital stay, serial cranial ultrasonographic examinations were performed and there was no abnormal finding including intraventricular haemorrhage or periventricular leukomalacia.

\section{DIFFERENTIAL DIAGNOSIS}

Among the infective and congenital causes of pleural effusion in neonates, the clinical course and a diagnostic paracentesis with the milky appearance and appropriate biochemical analysis of the pleural fluid supported the diagnosis of extravasation of parenteral nutrition solution of a mal-positioned CVC. Subsequently, the failed extubation following the clearance of pleural effusion and absence of significant respiratory diseases raised the suspicion of hemidiaphragmatic paralysis based on elevated right hemidiaphragm on chest X-ray. The hemidiaphragmatic paralysis was confirmed with an ultrasound examination, which also excluded the differential diagnoses of elevated right hemidiaphragm such as loculated subpulmonary effusion and subdiaphragmatic diseases. Although the clinical sign of paradoxical chest and abdominal movements would help the diagnosis in spontaneously breathing neonates, the sign may not be noticed in critically ill patients treated with mechanical ventilation. 


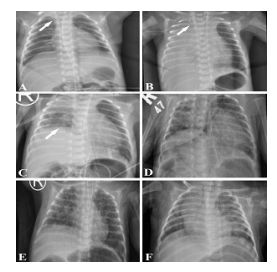

Figure 1 (A) Chest X-ray on day one after birth: mild RDS with tip of PICC at T2 (arrow) and no diaphragmatic abnormalities; (B) chest X-ray on day 2: right pleural effusion and tip of PICC at T2 (arrow); (C) chest $X$-ray on day 4: elevated diaphragmatic dome, and an asymmetry of position between the left and right hemidiaphragms; (D) prone chest $X$-ray on day 37: affected right side two intercostal spaces higher than left side with prone position. (E) chest $X$-ray on day 49 before successful extubation, (F) chest $X$-ray on day 97: recovery of normal diaphragmatic position. PICC, peripherally inserted central catheter; RDS, respiratory distress syndrome.

\section{TREATMENT}

The patient subsequently developed bronchopulmonary dysplasia with persistent hemidiaphragmatic paralysis (figure 1D,E). She was successfully extubated on D53 to biphasic continuous positive airway pressure with the use of systemic corticosteroids after improved diaphragmatic function was confirmed. Nasal continuous positive airway pressure was discontinued on D73 with no supplemental oxygen needed. Further serial ultrasound examinations demonstrated normal movements of both hemidiaphragms by D76 and the diaphragm position was normal on chest X-ray on D93 (figure 1F). The infant was discharged home without supplementary oxygen on D105.

\section{OUTCOME AND FOLLOW-UP}

The infant had no visit to emergency room or hospitalisation, except for a mild upper respiratory infection 1 month after discharge. In the follow-up at the multidisciplinary assessment and care clinic at 6 months corrected age, her growth was satisfactory. The respiratory examination was normal, and she demonstrated appropriate neurodevelopmental assessment. Diaphragmatic movements were normal and symmetrical in ultrasonic examination.

\section{DISCUSSION}

Hemidiaphragmatic paralysis in the neonatal period can be acquired and caused by unilateral phrenic nerve direct injury during CVC insertion, ${ }^{1}$ thoracic surgery, traumatic delivery (brachial plexus injury) ${ }^{2}$ and after catheter fluid extravasation from CVC. ${ }^{3-6}$ Extravasation may be due to vascular erosion of hyperosmolar parenteral nutritional solution (usually $>800 \mathrm{mOsm} / \mathrm{L}$ ), and hyperosmotic toxicity to the phrenic nerve. $^{7}$ Hyperosmolar parenteral nutritional solution also increases vascular permeability and thrombosis. ${ }^{8}$

In our case, the PICC tip was not centrally located, but initially sited in the subclavian vein. The phrenic nerve is derived from the cervical plexus and enters the thorax through the superior thoracic aperture, between the subclavian artery and subclavian vein. The intrathoracic course of phrenic nerve is close to the pericardium with a posterolateral course to the hemidiaphragm. We believe an injury to the phrenic nerve is very unlikely but not impossible because superficial needle thoracocentesis was performed. If parenteral nutrition solution is extravasated from subclavian vein, a local mechanical injury and/or toxicity to the phrenic nerve could be caused. This appears the most likely

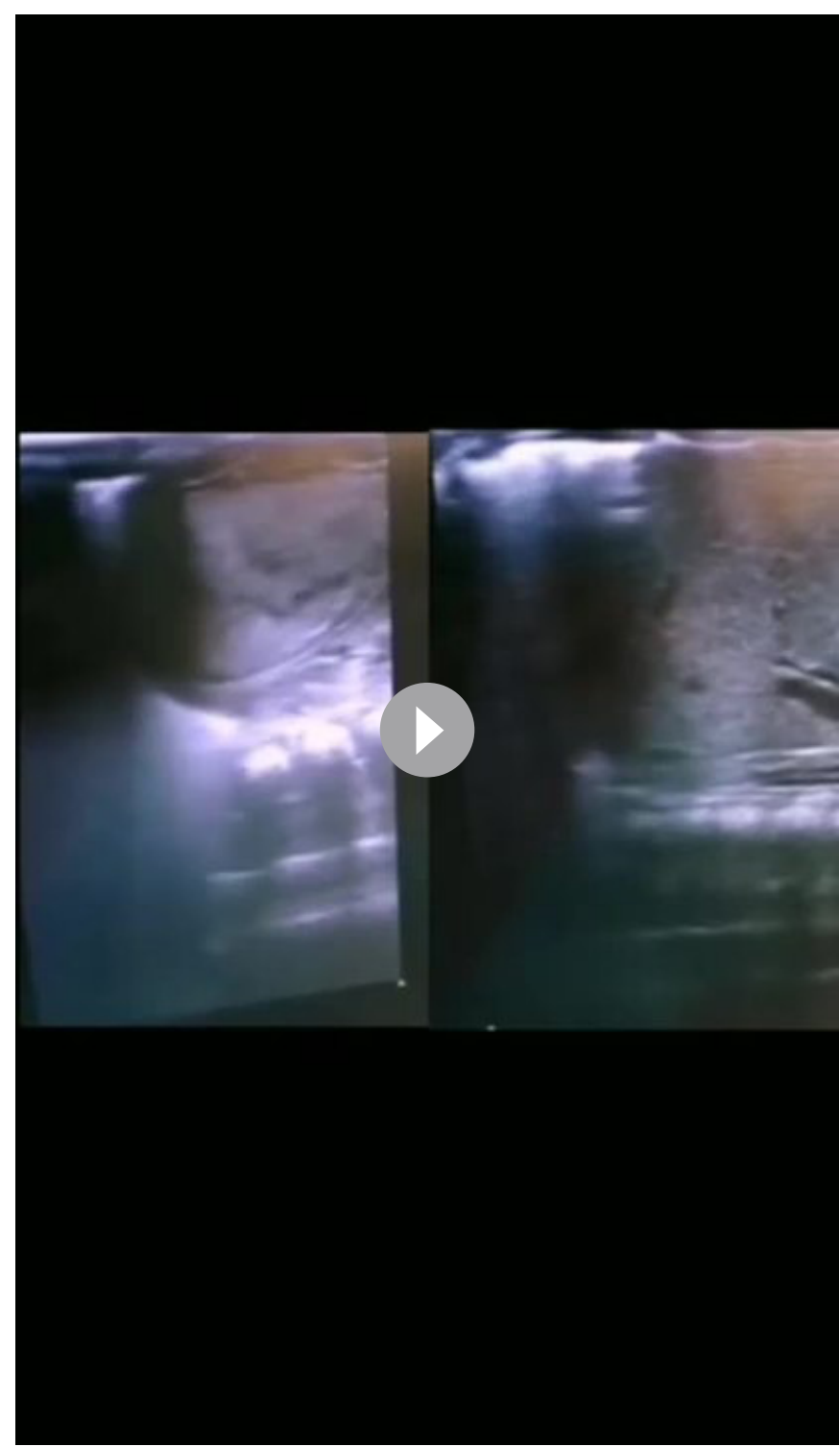

Video 1 Ultrasound examination of left (left panel) and right (right panel) hemidiaphragms showing the regular and sluggish movements, respectively.

scenario given the oedema of the right neck and shoulder during the event.

Phrenic nerve damage from PICC extravasation is uncommon. We only identified five previous reports in VLBW neonates (table 1)..$^{3-6}$ In these neonates, the PICC were not centrally located at insertion $(3,5$, our case) or subsequently migrated to a more peripheral location. ${ }^{4}$ Three $(50 \%)$ cases of hemidiaphragmatic paralysis were related to local extravasation of parenteral nutrition solution without pleural effusion, ${ }^{34}$ and PICC-related pleural effusion occurred in the other $3(50 \%)$ cases $(5,6$, our case). In a retrospective review of PICC-related pleural effusion in newborns which involved 926 PICCs, Bashir $e t$ al reported an incidence of PICC-related pleural effusion as $0.8 \%$ per catheter (0.4 per 1000 catheter days). ${ }^{9}$ Vascular erosion from the catheter is a rare complication with an incidence of $0.4 \%-0.7 \%{ }^{910}$ and a predominance in left-sided catheters. ${ }^{10}$

Clinical symptoms suggesting the diagnosis of hemidiaphragmatic paralysis include respiratory distress or failure to wean from ventilator (4/6), local signs (4/6) and infection (3/6) (table 1), none of 


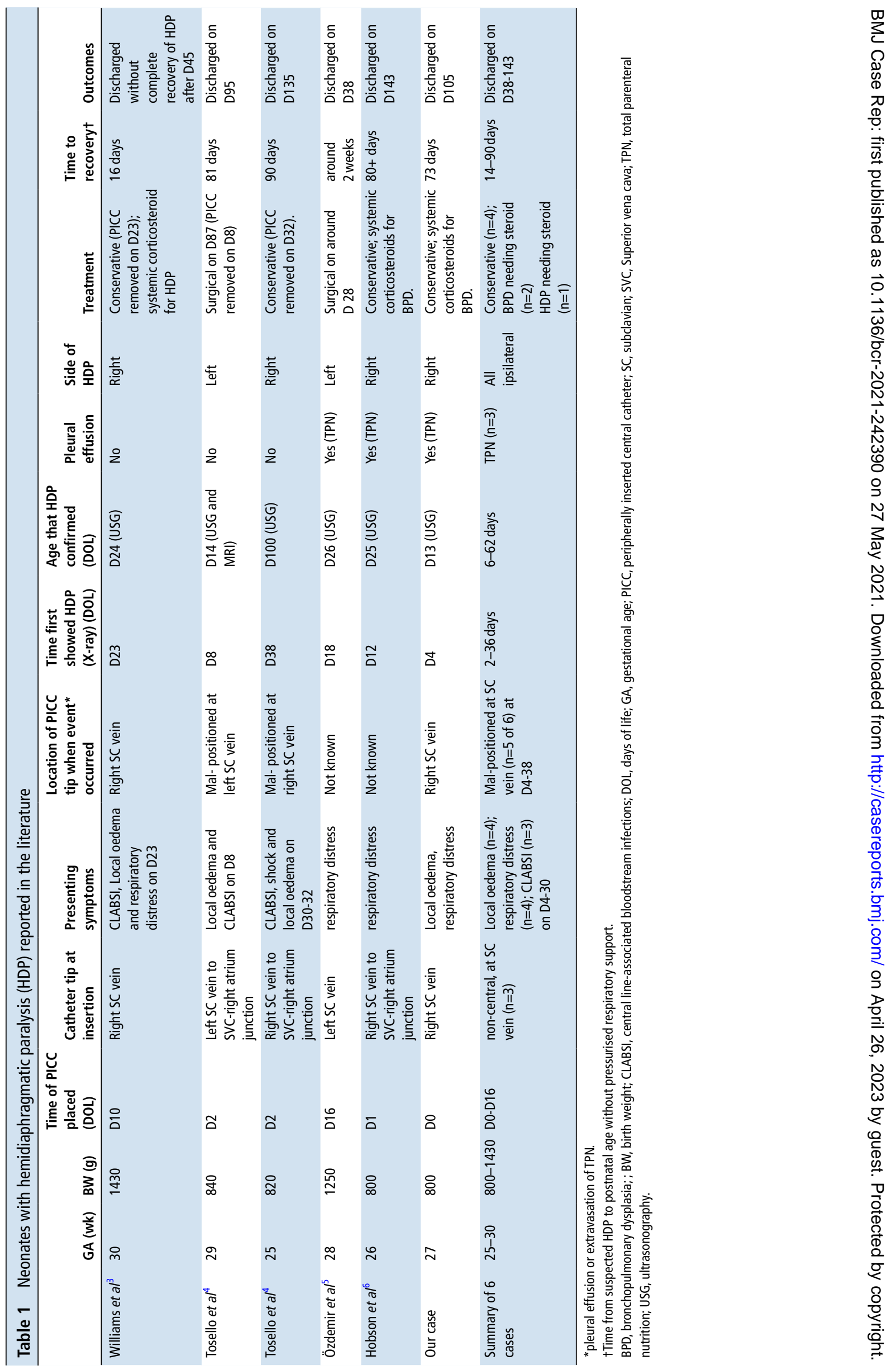


which are discriminating from other causes of respiratory failure in VLBW neonates. Hemidiaphragmatic paralysis is suspected when there is an elevation of the diaphragmatic dome on chest radiograph. In our case, elevated diaphragmatic dome was noted on D4 with the confirmation of hemidiaphragmatic paralysis by ultrasonography 9 days later. Indeed, there was an interval ranging from 6 to 62 days between the initial radiographic examination and the confirmation by ultrasonography or MRI (table 1).

Among these six VLBW neonates with hemidiaphragmatic paralysis, four were managed conservatively. The indications and timing for surgical intervention (diaphragmatic plication) are not clearly defined. Early surgery could reduce incidence of pulmonary infections, duration of mechanical ventilation and hospital stay. ${ }^{5}$ Moreover, in preterm neonates, invasive respiratory support is associated with ventilator-induced lung injury, bronchopulmonary dysplasia and increased risk of retinopathy of prematurity. On the other hand, anaesthesia and thoracic surgery may pose significant risks in these VLBW neonates with respiratory insufficiency receiving invasive mechanical ventilation. Two neonates had their diaphragms plicated and discharged about 10 days postoperatively. ${ }^{45}$ In contrast, it took our case 93 days of spontaneous fully recovery of hemidiaphragmatic paralysis (figure $1 \mathrm{~F}$ ). This further supports the cause being direct toxic injury from parenteral nutrition solution.

The use of corticosteroids in these VLBW neonates with respiratory insufficiency and bronchopulmonary dysplasia is controversial. Corticosteroids decrease the inflammation caused by extravasation thus improve diaphragmatic functional recovery but may adversely affect muscular growth and development of the diaphragm. Corticosteroids was used in three neonates with hemidiaphragmatic paralysis as the specific indication in one ${ }^{3}$ and bronchopulmonary dysplasia in two (6, our case). We used a 3-day course of low-dose dexamethasone to avoid the side effects in neurodevelopment. Meanwhile we adopted positional

\section{Patient's perspective}

Both parents of the baby praised the conservative care by the staff and said that we were happy with the spontaneous recovery of hemidiaphragmatic paralysis and the outcome of our girl. They commented that, as many other parents with sick children, conservative management rather than surgical approach was appreciated because surgical treatment should be used as the last resort as for most illnesses in children.

Learning points

- Very low birthweight (VLBW) neonates commonly needs the placement of central venous catheter for parenteral nutrition.

- Complications of central venous catheter placement include extravasation of parenteral nutrition solution causing local oedema and or pleural effusion, rarely hemidiaphragmatic paralysis.

- VLBW neonates with hemidiaphragmatic paralysis occurred over a variable of time after the malposition of central venous catheter associated with of extravasation of parenteral nutrition solution.

- Spontaneous recovery is possible with conservative management.
Kangaroo care, minimal sedative medications and synchronised and volume targeted mechanical ventilation, plus pressure support during weaning from invasive mechanical ventilation.

As shown in table 1, recovery was spontaneous in 14-90 days. In this review, the development of hemidiaphragmatic paralysis in VLBW neonates could be related to suboptimal location of PICC with or without extravasation of parenteral nutrition solution. Due to retrospective nature and small sample size, the review is limited by variations in the diagnosis and management of hemidiaphragmatic paralysis in VLBW neonates. Although there is no specific recommendation for the treatment of hemidiaphragmatic paralysis, this case series highlight the possibility of conservative management in VLBW neonates with hemidiaphragmatic paralysis.

Acknowledgements All authors are grateful to the medical and nursing care provided by Dr. JP Tian, Ms. YZ Yi and Ms. Y Xue and NICU staff as well as the advice from Professor NS Tsoi and Professor CB Chow during the hospitalisation and follow-up visits.

Contributors $\mathrm{H}-\mathrm{BH}$ conceptualised and designed the study, drafted the initial manuscript and reviewed and revised the manuscript. P-YC conceptualised and designed the study, supervised clinical information/data collection, critically reviewed and revised the manuscript. Q-SZ conceptualised and involved in clinical information/ data collection, and critically reviewed the manuscript for important intellectual content. DGT conceptualised and supervised in clinical information/data collection and critically reviewed the manuscript for important intellectual content. All authors were involved in the care of the patient at various stages of the clinical course. All authors approved the final manuscript as submitted and agreed to be accountable for all aspects of the work.

Funding This study was funded by Shenzhen SanMing Project of Medicine (SZSM 201911016); National Health and Medical Research Council Clinical Career Development Fellowship (1053889).

Competing interests None declared.

Patient consent for publication Obtained.

Ethics approval Obtained.

Provenance and peer review Not commissioned; externally peer reviewed.

Open access This is an open access article distributed in accordance with the Creative Commons Attribution Non Commercial (CC BY-NC 4.0) license, which permits others to distribute, remix, adapt, build upon this work non-commercially, and license their derivative works on different terms, provided the original work is properly cited and the use is non-commercial. See: http://creativecommons.org/ licenses/by-nc/4.0/.

\section{REFERENCES}

1 Aggarwal S, Hari P, Bagga A, et al. Phrenic nerve palsy: a rare complication of indwelling subclavian vein catheter. Pediatr Nephrol 2000;14:203-4.

2 Bowman ED, Murton LJ. A case of neonatal bilateral diaphragmatic paralysis requiring surgery. Aust Paediatr J 1984;20:331-2.

3 Williams JH, Hunter JE, Kanto WP, et al. Hemidiaphragmatic paralysis as a complication of central venous catheterization in a neonate. J Perinatol 1995; 15:386-8.

4 Tosello B, Michel F, Merrot T, et al. Hemidiaphragmatic paralysis in preterm neonates: a rare complication of peripherally inserted central catheter extravasation. J Pediatr Surg 2011:46:e17-21.

5 Özdemir R, Oğuz S, Uras N. Phrenic nerve injury due to thoracentesis for TPN effusion in a preterm newborn: consecutive two unusual complications. Tuberk Toraks 2011;59:384-7.

6 Hobson C, Dubillot D, Lardy $\mathrm{H}$, et al. A rare complication of central venous catheter extravasation in a preterm neonate: Hemidiaphragmatic paralysis. AJP Rep 2017:07:e65-7.

7 Hannon MG, Lee SK. Extravasation injuries. J Hand Surg Am 2011;36:2060-5.

8 Blackwood BP, Farrow KN, Kim S, et al. Peripherally inserted central catheters complicated by vascular erosion in neonates. JPEN J Parenter Enteral Nutr 2016;40:890-5.

9 Bashir RA, Callejas AM, Osiovich HC, et al. Percutaneously inserted central CatheterRelated pleural effusion in a level III neonatal intensive care unit: a 5-year review (2008-2012). JPEN J Parenter Enteral Nutr 2017:41:1234-9.

10 Mukau L, Talamini MA, Sitzmann JV. Risk factors for central venous catheter-related vascular erosions. JPEN J Parenter Enteral Nutr 1991:15:513-6. 
Copyright 2021 BMJ Publishing Group. All rights reserved. For permission to reuse any of this content visit https://www.bmj.com/company/products-services/rights-and-licensing/permissions/

BMJ Case Report Fellows may re-use this article for personal use and teaching without any further permission.

Become a Fellow of BMJ Case Reports today and you can:

- Submit as many cases as you like

Enjoy fast sympathetic peer review and rapid publication of accepted articles

Access all the published articles

Re-use any of the published material for personal use and teaching without further permission

Customer Service

If you have any further queries about your subscription, please contact our customer services team on +44 (0) 2071111105 or via email at support@bmj.com.

Visit casereports.bmj.com for more articles like this and to become a Fellow 